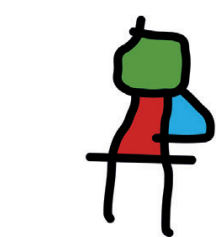

SEICAIP

\section{Allergologia et immunopathologia}

Sociedad Española de Inmunología Clínica, Alergología y Asma Pediátrica

www.all-imm.com

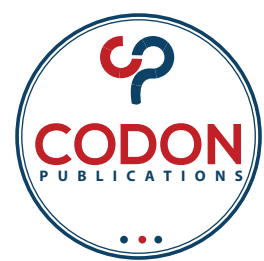

ORIGINAL ARTICLE

OPEN ACCESS (c)

\title{
22q11.2 deletion syndrome: 20 years of experience from two pediatric immunology units and review of clues for diagnosis and disease management
}

\author{
Selime Ozen ${ }^{a *}$, Omer Akcala, Ilke Taskirdia, Idil Akay Hacia, Neslihan Edeer Karacab, \\ Nesrin Gulez ${ }^{a}$, Guzide Aksub ${ }^{b}$ Ferah Genel ${ }^{a}$, Necil Kutukculer ${ }^{b}$
}

${ }^{a}$ Department of Pediatrics, Division of Allergy and Immunology, SBU Izmir Dr Behcet Uz Children's Education and Research Hospital, Izmir, Turkey

${ }^{b}$ Department of Pediatrics, Division of Immunology, Ege University Faculty of Medicine, Izmir, Turkey

Received 2 June 2020; Accepted 3 October 2020

Available online 2 January 2021

\section{KEYWORDS \\ Infections; \\ Immunodeficiency; \\ Thymus, pediatric, \\ 22q11.2 deletion \\ syndrome}

\begin{abstract}
Introduction and objectives: The purpose of this study was to evaluate patients diagnosed with 22q11.2 deletion syndrome and determine the clues directing to diagnosis and evaluation of immunological findings for excellent management of the disease.

Material and methods: Thirty-three pediatric patients with 22q11.2 deletion syndrome diagnosed between 1998 and 2019 at Pediatric Immunology Division of Ege University Faculty of Medicine and SBU Izmir Dr Behcet Uz Children's Education and Research Hospital were evaluated.

Results: This study includes the largest case series reported from Turkey. Congenital cardiac anomalies were the most common pathology associated with the syndrome (90.9\%). Hypocalcemic symptoms were observed in 13 patients (40\%). Twenty-two of the $33(66.6 \%)$ patients were diagnosed before two years of age. Autoimmune diseases, dysmorphic facial findings, recurrent infections, growth retardation, and speech impairment were other clues for diagnosis in older patients. Clinical spectrum and immunological abnormalities of this syndrome are quite variable. All T-cell subset counts were less than 5 th percentile below median by age in one patient (3\%) and 10 patients had normal all T-cell subset counts (30.3\%). Overall, $69.6 \%$ of the patients had normal IgG, IgA, and IgM levels and two patients had panhypogammaglobulinemia. Recurrent infections were revealed in $75.7 \%$ of the patients during follow-up. Conclusions: Presence of cardiac anomaly is more helpful in the diagnosis, especially under two years of age. Patients with immunologically high or standard risk did not show any difference in terms of numbers and severity of infections and autoimmunity.
\end{abstract}

(C) 2021 Codon Publications. Published by Codon Publications.

*Corresponding author: Selime Ozen, Department of Pediatrics, Division of Allergy and Immunology, SBU Izmir Dr Behcet Uz Children's Education and Research Hospital, Izmir, Turkey. Email address: yarenseli85@hotmail.com 


\section{Introduction}

22q11.2 deletion syndrome, also known as DiGeorge syndrome or velocardiofacial syndrome, is the most common chromosome deletion syndrome with an incidence of almost $1 / 4000$ live births. ${ }^{1}$ The clinical features are associated with the developmental defects in the third and fourth pharyngeal pouches. Heart, thymus, and parathyroid glands are derived from common primordia during embryonic development. The clinical features come in view by influence of these structures in varying degrees and there is an evident phenotypic heterogeneity. Dysmorphic facies (hypertelorism, eyelid hooding, low-set ears, bulbous nasal tip, short philtrum, a small mouth, and micrognathia), cardiac anomalies, pharyngeal dysfunction, hypoparathyroidism, and immunodeficiency are the most characteristic features. The spectrum of the severity of immunodeficiency varies and is associated with the dysfunction due to aplasia or hypoplasia of the thymus. As a result, T-cell production and maturation may be affected. Less than $0.5 \%$ of patients have reduced $\mathrm{CD} 3+\mathrm{T}$-cell counts (less than $50 / \mathrm{mm}^{3}$ ) related with athymia. ${ }^{2}$ They are defined as complete DiGeorge syndrome. The patients who are defined as partial DiGeorge syndrome have mild or moderately low T-cell counts. There is no correlation between phenotypic features and the severity and frequency of the immunodeficiency. ${ }^{3}$

The clinical findings and the severity of immunodeficiency may be associated with the deletion size of $22 q 11.2$ and some other factors, and may vary widely. ${ }^{4}$ This study aimed to analyze the common clinical and immunological features of the cases diagnosed with 22q11.2 deletion in a group of 33 patients. The authors tried to identify the clues leading to the diagnosis, and to review management of the disease. Our case series also includes the largest number of patients reported from Turkey.

\section{Patients and methods}

Thirty-three pediatric patients diagnosed with 22q11.2 deletion syndrome in Pediatric Immunology Division of Ege University Faculty of Medicine and SBU Izmir Dr Behcet Uz Children's Education and Research Hospital between 1998 and 2019 were evaluated. Medical records were retrospectively examined for each patient. Gender of patients, age at diagnosis, family history, diagnostic findings at admission, neonatal hypocalcemia, cardiac antenatal sonographic findings, gestational age, consanguinity, pathological physical examination findings during follow-up, thymus aplasia/hypoplasia, presence of cardiac, palatal, and skeletal, endocrinological, neurological, hematological, urinary, and gastrointestinal system anomalies, and speech disorders were evaluated. Immunological parameters at diagnosis and follow-up were recorded. The diagnosis was confirmed by demonstration of 22q11.2 deletion by Fluorescence in situ hybridization (FISH). The frequency and types of infections and treatment regimens during the follow-up were examined.

All patients were evaluated for complete blood count, immunoglobulin levels (IgG, IgA, and IgM), and lymphocyte subtypes at the time of diagnosis and follow-up. Serum immunoglobulin levels were determined using nephelometric technique, and low immunoglobulin levels were defined as Standard Deviation $(S D)<2$ below the mean value of age. ${ }^{5}$ Lymphocyte immunophenotyping was performed by a flow cytometer using erythrocyte-lysed whole blood procedure. The following conjugated monoclonal antibodies were used: CD45/CD14 for the establishment of an optimal lymphocyte gate, CD3/CD19 for the detection of $\mathrm{T}$ and $\mathrm{B}$ lymphocytes, CD3/CD4 for the detection of helper $T$ lymphocytes, CD3/CD8 for the detection of cytotoxic $T$ lymphocytes, and $\mathrm{CD} 3 / \mathrm{CD} 16+56$ to detect natural killer cells. Appropriate isotype controls were used to evaluate nonspecific staining. For each sample, 10,000 events were acquired. Samples were analyzed, and lymphocyte percentages were calculated. Cell numbers per cubic milliliter of blood were obtained using lymphocyte counts from the complete blood count. The patients were regarded as having low lymphocyte subset percentage and count when their levels were less than the 5 th percentile below the median by age. ${ }^{6}$

Statistical analysis was performed using SPSS version 18.0. Standard statistical descriptions of variables were used to characterize the data (mean, median, and range). Categorical variables were evaluated by using Chi-square test. $\mathrm{P}<0.05$ was considered statistically significant.

\section{Results}

All the 33 patients diagnosed as having DiGeorge syndrome in our clinics between 1998 and 2019 were examined. The diagnosis was verified by genetic analysis for each patient and 22q11.2 deletion was detected in all. Sixteen of the patients were girls (48.5\%) and 17 were boys (51.5\%). Mean age at diagnosis was $29.8 \pm 39.2$ months and median age was eight months (range antenatal to 135 months). The patient with the lowest age at diagnosis was determined by antenatal amniocentesis because of abnormal antenatal cardiac sonographic finding. Isolated hypocalcemic convulsion was the first clue for the diagnosis of a 135-month-old boy who was the oldest patient at the time of diagnosis. Congenital cardiac anomaly in 25 patients (75\%), isolated hypocalcemic convulsions in four patients (12\%), and autoimmune cytopenia in two patients $(6 \%)$ were the first diagnostic clues suggesting the diagnosis of the 22q11.2 deletion syndrome (Table 1). Growth retardation and speech disorder were the other major complaints at admission. Twenty-two of the $33(66.6 \%)$ patients were diagnosed before two years of age. As congenital heart disease and hypocalcemia were the most important findings at admission, these were also evaluated according to age groups. Although both findings were higher in patients aged less than 2 years than in patients aged more than two years, the presence of congenital heart disease was statistically significant $(P=0.04)$ (Table 2). In patients aged more than two years in addition to congenital heart disease and hypocalcemia, autoimmune diseases, dysmorphic facial findings, recurrent infections, growth retardation, and speech disorder were also the clues for diagnosis.

Five of the patients had preterm labor and five had consanguinity. The most frequent pathology determined in patients was the cardiac anomaly $(90.9 \%)$ (Table 3$)$. Thirty patients had different pathologies with echocardiographic 
Table 1 Clues suggesting the diagnosis of 22q11.2 deletion syndrome.

\begin{tabular}{|c|c|c|}
\hline & \multicolumn{2}{|c|}{ Age at diagnosis } \\
\hline Clinical presentation & $\begin{array}{l}<2 \text { years } \\
\text { Total } n=22 \\
n(\%)\end{array}$ & $\begin{array}{l}\geq 2 \text { years } \\
\text { Total } \\
n=11 \\
n(\%)\end{array}$ \\
\hline Congenital cardiopathy & $8(24.2)$ & $5(15.1)$ \\
\hline $\begin{array}{l}\text { Congenital } \\
\text { cardiopathy }+ \text { Neonatal } \\
\text { hypocalcemia }\end{array}$ & $6(18.1)$ & - \\
\hline $\begin{array}{l}\text { Congenital } \\
\text { cardiopathy + perioperative } \\
\text { thymus agenesis }\end{array}$ & $2(6.0)$ & - \\
\hline $\begin{array}{l}\text { Congenital cardiopathy }+ \text { cleft } \\
\text { palate }\end{array}$ & $3(9.0)$ & - \\
\hline $\begin{array}{l}\text { Congenital } \\
\text { cardiopathy + recurrent } \\
\text { infections }\end{array}$ & - & $1(3.0)$ \\
\hline $\begin{array}{l}\text { Isolated hypocalcemic } \\
\text { seizure }\end{array}$ & $2(6.0)$ & $2(6.0)$ \\
\hline $\begin{array}{l}\text { Autoimmune } \\
\text { cytopenia + dysmorphic } \\
\text { facial findings }\end{array}$ & - & $1(3.0)$ \\
\hline $\begin{array}{l}\text { Autoimmune Cytopenia }+ \\
\text { Polymicrogyria }+ \\
\text { Lymphopenia }+ \text { Central } \\
\text { facial nerve paralysis }\end{array}$ & $1(3.0)$ & - \\
\hline Growth retardation & - & $1(3.0)$ \\
\hline Speech disorder & - & $1(3.0)$ \\
\hline
\end{tabular}

Table 2 Congenital heart disease and hypocalcemia as presenting findings according to age groups.

\begin{tabular}{|c|c|c|c|}
\hline $\begin{array}{l}\text { Age at } \\
\text { diagnosis }\end{array}$ & $\begin{array}{l}\text { Patient presentation } \\
\text { Hypocalcemia }(+) \\
\text { Total } n=10 n(\%)\end{array}$ & $\begin{array}{l}\text { Hypocalcemia (-) } \\
\text { Total } n=23 n(\%)\end{array}$ & $P$ \\
\hline$<2$ years & $8(36.4)$ & $14(63.6)$ & 0.28 \\
\hline \multirow[t]{2}{*}{$\geq 2$ years } & $2(18.2)$ & 9 (81.8) & \\
\hline & $\begin{array}{l}\text { Cardiopathy }(+) \\
\text { total } n=25\end{array}$ & $\begin{array}{l}\text { Cardiopathy }(-) \\
\text { Total } n=8\end{array}$ & \\
\hline$<2$ years & $19(82.6)$ & $3(13.6)$ & 0.04 \\
\hline$\geq 2$ years & $6(54.5)$ & $5(45.5)$ & \\
\hline
\end{tabular}

examination. Congenital cardiopathy was detected during routine examination in five patients who were admitted with different symptoms and clinical findings. Conotruncal (truncus arteriosus, tetralogy of Fallot, and double outlet right ventricle) and aortic arch defects were determined in 14 patients $(42.4 \%)$. All patients had characteristic facial features associated with $22 q 11.2$ deletion. Thymus was not evaluated in eight patients $(25 \%)$ by radiological investigations or during cardiac operations.

Hypocalcemic symptoms caused by hypoparathyroidism were observed in 13 patients $(40 \%)$, and 10 of these were neonatal hypocalcemia (Table 3 ). Isolated hypocalcemic
Table 3 Distribution of all clinical findings in patients with 22q11.2 deletion.

\begin{tabular}{|c|c|c|c|}
\hline & & $\%$ & $n$ \\
\hline \multirow[t]{8}{*}{ Cardiac defects } & 90.9 & Aortic arch anomalies & 5 \\
\hline & & VSD isolated & 5 \\
\hline & & Tetralogy of Fallot & 3 \\
\hline & & AS desolated & 3 \\
\hline & & Truncus arteriosus & 2 \\
\hline & & $\begin{array}{l}\text { Double outlet right } \\
\text { ventricle }\end{array}$ & 2 \\
\hline & & Interrupted aortic arch & 2 \\
\hline & & Others & 8 \\
\hline \multirow{3}{*}{$\begin{array}{l}\text { Endocrine } \\
\text { disorders }\end{array}$} & 57.5 & Hypoparathyroidism & 13 \\
\hline & & Hypothyroidism & 5 \\
\hline & & Diabetes & 1 \\
\hline Speech delay & 27.2 & & 9 \\
\hline \multirow[t]{2}{*}{ Palatal anomaly } & 27.2 & $\begin{array}{l}\text { Cleft palate/high arch } \\
\text { palate/bifiduvula }\end{array}$ & 9 \\
\hline & & Pes equinovarus & 4 \\
\hline \multirow[t]{2}{*}{ Skeletal anomaly } & 24.2 & Scoliosis & 3 \\
\hline & & Vertebral fusion defect & 1 \\
\hline \multirow{2}{*}{$\begin{array}{l}\text { Urogenital } \\
\text { abnormalities }\end{array}$} & 15.1 & Renal agenesis & 3 \\
\hline & & Epi-hypospadias & 2 \\
\hline $\begin{array}{l}\text { Gastrointestinal } \\
\text { abnormalities }\end{array}$ & 12.1 & $\begin{array}{l}\text { Gastroesophageal reflux } \\
\text { Ileal atresia }\end{array}$ & $\begin{array}{l}3 \\
1\end{array}$ \\
\hline \multirow{3}{*}{$\begin{array}{l}\text { Neurological } \\
\text { abnormalities }\end{array}$} & 9 & Post-eriorfossa cyst & 1 \\
\hline & & $\begin{array}{l}\text { Polymicrogyria + central } \\
\text { facial palsy + left } \\
\text { hemiparesis }\end{array}$ & 1 \\
\hline & & $\begin{array}{l}\text { Mixed-type } \\
\text { polyneuropathy }\end{array}$ & 1 \\
\hline $\begin{array}{l}\text { Hematological } \\
\text { abnormalities }\end{array}$ & 9 & Autoimmune cytopenia & 3 \\
\hline
\end{tabular}

convulsion was the cardinal symptom of the DiGeorge syndrome in four patients aged eight months, nine months, eight years, and 11 years. The pathogenesis of autoimmune disorders in DiGeorge syndrome is not well known. Four of our patients $(12.1 \%)$ had autoimmune manifestations, one patient had only autoimmune thyroiditis, and one patient had autoimmune thrombocytopenia. Autoimmune pancytopenia was determined in two of the patients. A four-year-old girl presented with autoimmune thrombocytopenia and in follow-up, she developed subacute chronic dermatitis, hemolytic anemia, autoimmune arthritis, and thyroiditis. When she was 18 years old, multiple autoimmune disorders occurred. Immune suppressive treatment and immunoglobulin replacement treatment were given, but unfortunately, she died because of resistant inflammation, sepsis, and multiple organ failure. An eight-month-old girl with congenital polymicrogyria, central facial nerve paralysis, and left-hemiparesis was admitted to the hospital due to autoimmune pancytopenia. Because of her dysmorphic facial findings and severe lymphopenia, FISH test was performed and DiGeorge syndrome was diagnosed. Immunosuppressive treatments such as corticosteroid, rituximab, and mycophenolate mofetil were used in addition to immunoglobulin replacement therapy in patients with autoimmune findings. 
Table 4 Mean levels of immunoglobulin isotypes and lymphocyte subgroup counts and ratios of the patients.

\begin{tabular}{lcll}
\hline & Mean \pm SD & Min & Max \\
\hline IgG $(\mathrm{mg} / \mathrm{dL})$ & $748.4 \pm 258.1$ & 140 & 1570 \\
IgA $(\mathrm{mg} / \mathrm{dL})$ & $72.5 \pm 64.1$ & 6 & 295 \\
IgM(mg/dL) & $61.5 \pm 33.1$ & 17 & 132 \\
Absolutelymphocytecount & $4029.3 \pm 2828.1$ & 920 & 7796 \\
$\quad\left(\# / \mathrm{mm}^{3}\right)$ & & & \\
CD19 $(\%)$ & $27.8 \pm 10.3$ & 11.5 & 54.4 \\
CD19 $\left(\# / \mathrm{mm}^{3}\right)$ & $1155.7 \pm 823$ & 122 & 2879 \\
CD3 $(\%)$ & $47.7 \pm 16.9$ & 5.8 & 80.3 \\
CD3 $\left(\# / \mathrm{mm}^{3}\right)$ & $1809.2 \pm 1193.2$ & 309 & 4448 \\
CD4 $(\%)$ & $27.9 \pm 11.3$ & 4.7 & 59 \\
CD4 $\left(\# / \mathrm{mm}^{3}\right)$ & $1124.8 \pm 787.5$ & 174 & 2962 \\
CD8 $(\%)$ & $21 \pm 10.6$ & 0.5 & 50 \\
CD8 $\left(\# / \mathrm{mm}^{3}\right)$ & $825 \pm 630.9$ & 30 & 2610 \\
CD16/56 $(\%)$ & $20.8 \pm 10.5$ & 2 & 45 \\
CD16/56 $\left(\# / \mathrm{mm}^{3}\right)$ & $788.1 \pm 472.9$ & 57 & 1857 \\
\hline
\end{tabular}

Immunological spectrum of the patients was highly variable (Table 4). In five patients, absolute lymphocyte counts were low compared to age-related normal values (Table 5). Twenty-one patients had low CD3+ T-cell counts, 19 patients had low CD4+ T-cell counts, and 11 patients had low CD8+ T-cell counts. Ten patients had normal T-cell percentages and T-cell subset counts (30.3\%). Overall, $69.6 \%$ of the patients had normal IgG, IgA, and IgM levels and two patients (6\%) had low IgA, IgG, and IgM levels at initial evaluation (Table 5). Other patients had at least one immunoglobulin level below the normal values.

Twenty-five of the 33 patients $(75.7 \%)$ had recurrent infections such as pneumonia and otitis media, 21 (63.6\%) of them used prophylactic antibiotic or antifungal (amoxicillin, trimethoprim-sulfamethoxazole, and fluconazole) in follow-up. Immunoglobulin replacement therapy was performed in 13 patients (39.4\%). Regular immunoglobulin and prophylactic antibiotics or antifungals are still used regularly in 12 of them. Prophylactic antibiotic was stopped in seven of them because of decreasing frequency of infections. One of the patients had tracheostomy and three had bronchiectasis. Immunosuppressive treatment was still used in one patient because of autoimmune cytopenia. One of our patients died during cardiac operation when he was 1.5 months old, and another one died because of sepsis and multiple organ failure when she was 18 years old. T-cell counts reached normal levels for their age in five patients who had low T-cell counts at initial examination. None of our patients had developed malignancy in follow-up.

\section{Discussion}

22q11.2 deletion syndrome is the most common microdeletion syndrome characterized by conotruncal cardiac anomaly, immunodeficiency, and hypocalcemia. However, the presence, severity, or onset age of the symptoms may be quite variable, it is sometimes available to access the diagnosis by other clues. According to our results, cardiac defects and hypocalcemia are the most
Table 5 Immunological findings of patients with $22 \mathrm{q} 11.2$ deletion.

\begin{tabular}{|c|c|c|}
\hline Lymphocyte subsets & $\begin{array}{c}\text { Number of patients } \\
\text { total } n=33\end{array}$ & $\%$ \\
\hline $\begin{array}{l}\text { Low absolute lymphocyte } \\
\text { count }\end{array}$ & 5 & 15.1 \\
\hline $\begin{array}{l}\text { Decreased } \mathrm{CD} 3+\mathrm{T} \\
\text { lymphocyte count }\end{array}$ & 21 & 63.6 \\
\hline $\begin{array}{l}\text { Decreased CD4+T } \\
\text { lymphocyte count }\end{array}$ & 19 & 57.5 \\
\hline $\begin{array}{l}\text { Decreased CD8+T } \\
\text { lymphocyte count }\end{array}$ & 11 & 33.3 \\
\hline $\begin{array}{l}\text { Decreased CD19+ } \\
\text { Blymphocyte count }\end{array}$ & 1 & 3 \\
\hline DecreasedNKcellcount & 1 & 3 \\
\hline $\begin{array}{l}\text { Decreasedallof } \\
\text { lymphocytesubsets }\end{array}$ & 1 & 3 \\
\hline $\begin{array}{l}\text { Normal all of } \\
\text { lymphocyte subsets }\end{array}$ & 10 & 30.3 \\
\hline Immunoglobulin levels & $\begin{array}{l}\text { Number of patients } \\
\text { Total } n=33\end{array}$ & $\%$ \\
\hline Low IgG level & 5 & 15.1 \\
\hline LowlgM level & 10 & 30.3 \\
\hline LowlgA level & 7 & 21.2 \\
\hline Panhypogamaglobulinemia & 2 & 6 \\
\hline IgG,IgA,IgMare allnormal & 23 & 69.6 \\
\hline
\end{tabular}

common features leading to diagnosis like other studies. ${ }^{7}$ Cardiac defects or hypocalcemia in newborns with facial features should lead to 22q11.2 deletion research. The presence of characteristic facial features can assist in diagnosis of patients, but if other typical congenital features are absent, the opportunity for diagnosis can be missed. ${ }^{8}$ Especially under two years of age, the presence of cardiac anomaly or hypocalcemia is very helpful for the diagnosis. However, there were patients with hypocalcemic convulsion or autoimmune manifestations diagnosed at older ages in our study.

It is known that there is an enormous phenotypic heterogeneity in this syndrome. ${ }^{9}$ The frequency of cardiac anomalies in the literature is $49-83 \% .^{9}$ Cardiac defect was detected in $90.9 \%$ of our patients. The malformations of the outflow tract that include tetralogy of Fallot (with or without pulmonary atresia), truncus arteriosus, and interrupted aortic arch type $B$ are the most specific congenital heart defects in 22q11.2 deletion syndrome. ${ }^{8}$ Furthermore, these patients may have a normal echocardiographic examination or nonspecific cardiac defects other than typical cardiac manifestations. Congenital heart diseases are the most common cause of death in patients with 22q11.2 deletion syndrome $(87 \%))^{10,11}$

In Childhood Obesity Programme (CHOP) cohort data, ${ }^{12}$ the frequency of hypocalcemia is reported to be $49 \%$. Similar to this data, in our evaluation for symptomatic hypocalcemia due to hypoparathyroidism, it was reported in 13 patients $(39.3 \%)$. Ten of them were neonatal hypocalcemic (30.3\%). This ratio is reported as $20 \%$ in an Italian 
study. ${ }^{7}$ Hypocalcemic symptoms can manifest as transient neonatal hypocalcemia or new-onset hypocalcemia that related to stress and illness, preoperatively or during adolescence or pregnancy..$^{13}$ Hypothyroidism and diabetes were other endocrinological manifestations associated with this deletion in our cases.

Palatal anomalies associated with $22 \mathrm{q} 11.2$ deletion were reported at $69 \% .^{14}$ The frequency of palatal anomalies was $27.2 \%$ in our study. It is possible that minor palatal abnormalities were not recorded for our cases. Similarly, less speech disorder may be observed because of the underage of the patients and incomplete anamnestic data.

The previous studies reported developmental midline anomalies in brain concomitant with 22q11.2 deletion such as abnormalities of septum pellucidi, agenesis of corpus callosum, increased white matter hyperintensities, hypoplastic cerebellar vermis and cerebellar atrophy, and polymicrogyria. ${ }^{15}$ One of our patients had left hemiparesis and central facial paralysis. Polymicrogyria was determined in her brain MRI. The incidence of polymicrogyria in 22q11.2 deletion has been reported as $1 \% .^{15}$ The pathogenesis of polymicrogyria is unclear but hypoperfusion of the brain because of a vascular mechanism is a defended hypothesis. ${ }^{16}$ In addition, Schaer et al. ${ }^{17}$ reported that there was a correlation between significant congenital cardiac disease and the brain volume and gyrification. Our patient had a bicuspid aortic valve, which was not a severe cardiac anomaly in her echocardiography. However, autoimmune cytopenia was the significant finding when she was 14 months old. Walking disorder developed in one of our patients, who was operated because of pes equinovarus deformity. Mixed-type polyneuropathy was determined in his electromyographic examination. There is no similar case with mixed-type polyneuropathy in 22q11.2 deletion in literature. This was considered to be associated with pes equinovarus deformity or related operation with this situation.

22q11.2 deletion syndrome is characteristically related with T-cell immunity because of thymic aplasia/hypoplasia or abnormal thymic migration. However, defects in T-cell immunity are various and associated with the severity of immunodeficiency. ${ }^{18}$ The immunodeficiency related with this syndrome has a large range from life-threatening to normal immunity. ${ }^{18}$ Nain et al. ${ }^{19}$ defined patients with low CD4+ and CD8+ cells as "high risk patients" whereas patients with normal numbers of CD4+ and CD8+ T-cells were defined as "standard risk patients." The authors had detected more severe infections and persistent hypoparathyroidism in the high-risk group. At the time of diagnosis, $15.1 \%$ of our patients had a low absolute lymphocyte count, and a total of $63.6 \%$ of the patients had low CD4+ and/or CD8+ T-cell numbers (high-risk group). Ten of our patients (30.3\%) had a normal distribution of all lymphocyte subtypes (standard risk group). We could not find any significant difference between clinical findings in these two groups (data not shown).

Only one of our patients with diagnosed $22 q 11.2$ deletion was complete DiGeorge. He had all subtypes of lymphocytes low at diagnosis and no improvement was observed during eight years of follow-up. Thymic transplant is still an alternative treatment for this patient. According to Suksawat et al.'s ${ }^{20}$ study, median age of CD4+
T-cell recovery was 2.5 years in partial DiGeorge syndrome patients. Giardino et al. ${ }^{21}$ reported that the age-related recovery of $\mathrm{T}$-cell numbers depended on a homeostatic peripheral proliferation of T-cells as well as a more skewed T-cell repertoire in older partial DiGeorge syndrome patients. Reduced T-cell counts at initial stage had recovery in six patients during follow-up. The mean age of resolution was 67 months.

The B-side of DiGeorge syndrome was also investigated in recent studies. Total B-cell numbers were usually not affected but memory B-cells were low. ${ }^{18}$ In our data, there was only one patient who had decreased B-cell numbers. Twenty-three of the patients $(69.6 \%)$ had normal immunoglobulin levels and two patients (6\%) had panhypogammaglobulinemia. Ten patients (30.3\%) had low IgM levels, but these patients were in both high- and standard-risk groups.

It has been observed that there is an increased risk of autoimmune manifestations, although the reason for this remains unclear. ${ }^{18}$ Giardino et al. ${ }^{21}$ reported that autoimmunity was associated with persistently low IgM and lymphopenia levels. In Giardino's study, patients with autoimmunity showed lower levels of $\mathrm{CD3}+, \mathrm{CD} 3+\mathrm{CD} 4+$, and naive CD4+CD45RA+CD27+ T lymphocytes compared with DiGeorge patients without autoimmunity. ${ }^{21}$ In our study, there were four patients with clinical and laboratory signs of autoimmunity. One of these patients had more than one autoimmune process such as thyroiditis, diabetes, arthritis, and hemolytic anemia. Because of uncontrolled inflammation despite the immunosuppressive treatment, she died at the age of 18 due to multiple organ failure and sepsis. None of our patients with autoimmune findings showed any association with IgM levels, lymphocyte numbers, and $\mathrm{T}$ cell subsets.

The course and management of disease are directly related with the severity of cardiac anomaly, immunodeficiency, and the patient's age. Cardiac operations and calcium replacement treatment are often used before two years of age. Prophylactic antibiotic and antifungal treatment can be used in patients with recurrent sinopulmonary infections. Intravenous immunoglobulin therapy was administered to these patients for many purposes, such as replacement therapy for low IgG levels, insufficient specific antibody response, or to prevent serious pulmonary infections, although the patients have normal immunoglobulin levels. Thymus transplantation is rarely performed in complete DiGeorge syndrome patients. If there is a compatible donor and recurrent infections threatening life, hematopoietic cell transplantation could be an alternative treatment to thymus transplantation.

In this study, we have demonstrated the clinical and immunological data of quite a large number of patients with 22q11.2 deletion syndrome diagnosed in our clinics. In conclusion, cardiac anomalies are usually the first diagnostic clue in patients with 22q11.2 deletion. Especially under two years of age, the presence of cardiac anomaly is more helpful in diagnosis. However, the clinical spectrum of this syndrome varies considerably and there are also several immunological abnormalities. Patients with immunologically high or standard risks did not show any difference in terms of numbers and severity of infections and autoimmunity. We suggest that infections in these patients could be 
related with other factors, such as environmental conditions, anatomical complications, such as palatal anomalies, and poor disease management.

\section{Author contributions}

SO, OA, IT, IAH, NG, GA, and NEK: collected and analyzed the data. NK, FG, and SO: conceived and designed the study. SO: wrote the paper. NK and FG: supervised the study. All authors approved the final manuscript as submitted.

\section{Funding information}

The authors declare that no funding was received for the present study.

\section{Conflict of interest}

The authors declare that they have no conflict of interest.

\section{References}

1. Oskarsdóttir S, Vujic M, Fasth A. Incidence and prevalence of the 22q11 deletion syndrome: A population-based study in western Sweden. Arch Dis Child. 2004;89(2):148-51. https:// doi.org/10.1136/adc.2003.026880

2. Markert ML, Devlin BH, Alexieff MJ, Li J, McCarthy EA, Gupton SE, et al. Review of 54 patients with complete DiGeorge anomaly enrolled in protocols for thymus transplantation: Outcome of 44 consecutive transplants. Blood. 2007;109(10):4539-47. https://doi.org/10.1182/blood-2006-10-048652

3. Sullivan KE, Jawad AF, Randall P, Driscoll DA, Emanuel BS, McDonald-McGinn DM, et al. Lack of correlation between impaired T cell production, immunodeficiency and other phenotypic features in chromosome $22 \mathrm{q} 11.2$ deletion syndromes. Clin Immunol Immunopathol. 1998;86(2):141-6. https://doi. org/10.1006/clin.1997.4463

4. Rozas MF, Benavides F, Leon L, Repetto M. Association between phenotype and deletion size in 22q11.2 microdeletion syndrome: Systematic review and meta-analysis. Orphanet J Rare Dis. 2019;14:195-204. https://doi.org/10.1186/ s13023-019-1170-x

5. Aksu A, Genel F, Koturoglu G, Kurugol Z, Kutukculer N. Original serum immunoglobulin (IgG, IgM, IgA) and IgG subclass concentrations in healthy children: A study using nephelometric technique. Turkish J Pediatr. 2006;48(1):19-24. PMID: 16562781

6. Comans-Bitter WM, Groot R, Beemd R, Neijens HJ, Hop W CJ, Groeneveld $\mathrm{K}$, et al. Immunophenotyping of blood lymphocytes in childhood reference values for lymphocyte subpopulations. J Pediatr. 1996;130(3):388-93. https://doi.org/10.1016/ S0022-3476(97)70200-2

7. Cancrini C, Puliafito P, Digilio MC, Soresina A, Martino S, Rondelli $\mathrm{R}$, et al. Clinical features and follow-up in patients with 22q11.2 deletion syndrome. J Pediatr. 2014;164(6):147580. https://doi.org/10.1016/j.jpeds.2014.01.056

8. MCDonald-McGinn DM, Sullivan KE, Marino B, Philip N, Swillen A, Vorstman JAS, et al. 22q11.2 deletion syndrome. Nat Rev Dis Primers. 2015;1:1-19. https://doi.org/10.1038/nrdp.2015.71

9. Kobrynski LJ, Sullivan KE. Velocardiofacial syndrome, DiGeorge syndrome: The chromosome 22q11.2 deletion syndromes. Lancet. 2007;370:1443-52. https://doi.org/10.1016/ S0140-6736(07)61601-8

10. McDonald-McGinn DM, Tonnesen MK, Laufer-Cahana A, Finucane B, Driscoll DA, Emanuel BS, et al. Phenotype of the 22q11.2 deletion in individuals identified through an affected relative: Cast a wide FISHing net! Genet Med. 2001;3(1):23-9. https://doi.org/10.1097/00125817-200101000-00006

11. Repetto GM, Guzmán ML, Delgado I, Loyola H, Palomares M, Lay-Son $G$, et al. Case fatality rate and associated factors in patients with 22q11 microdeletion syndrome: A retrospective cohort study. BMJ Open. 2014;4(11):e005041. https://doi. org/10.1136/bmjopen-2014-005041

12. MCDonald-McGinn DM, Sullivan KE. Chromosome $22 \mathrm{q} 11.2$ deletion syndrome (DiGeorge syndrome/velocardiofacial syndrome). Medicine (Baltimore). 2011;90(1):1-18. https://doi. org/10.1097/MD.0b013e3182060469

13. Fung WLA, Butcher NJ, Costain G, Andrade DM, Boot E, Chow EWC, et al. Practical guidelines for managing patients with 22q11.2 deletion syndrome. Genet Med. 2015;17:599-609. https://doi.org/10.1038/gim.2014.175

14. Haskologlu ZS, Ikinciogullari A. Chromosome 22q11.2 deletion syndrome (DiGeorge syndrome/velocardiofacial syndrome). Turk J Immunol. 2014;2:57-66. https://doi.org/10.5606/tji. 2014.320

15. Bohm LA, Zhou TC, Mingo TJ, Dugan SL, Patterson RJ, Sidman JD, et al. Neuroradiographic findings in 22q11.2 deletion syndrome. Am J Med Genet A. 2017;173:2158-65. https://doi. org/10.1002/ajmg.a.38304

16. Robin NH, Taylor CJ, McDonald-McGinn DM, Zachai EH, Bingham $\mathrm{P}$, Collins $\mathrm{KJ}$, et al. Polymicrogyria and deletion 22q11.2 syndrome: Window to the etiology of a common cortical malformation. Am J Med Genet A. 2006;140(22):2416-25. https://doi.org/10.1002/ajmg.a.31443

17. Schaer M, Glaser B, Cuadra MB, Debbane M, Thiran JP, Eliez S. Congenital heart disease affects local gyrification in 22q11.2 deletion syndrome. Dev Med Child Neurol. 2009;51(9):746-53. https://doi.org/10.1111/j.1469-8749.2009.03281.x

18. McLean-Tooke A, Barge D, Spickett GP, Gennery AR. Immunologic defects in 22q11.2 deletion syndrome. J Allergy Clin Immunol. 2008;122(2):362-7. https://doi.org/10.1016/j. jaci.2008.03.033

19. Nain E, Kiykim A, Ogulur I, Kasap N, Karakoc-Aydiner E, Ozen A, et al. Immune system defects in DiGeorge syndrome and association with clinical course. Scand J Immunol. 2019;90(5):e12809. https://doi.org/10.1111/sji.12809

20. Suksawat Y, Sathienkijkanchai A, Veskitkul J, Jirapongsananuruk $\mathrm{O}$, Visitsunthorn $\mathrm{N}$. Resolution of primary immune defect in 22q11.2 deletion syndrome. J Clin Immunol. 2017;37(2):375-82. https://doi.org/10.1007/s10875-017-0394-6

21. Giardino G, Radwan N, Koletsi P, Morrogh DM, Adams S, Ip $\mathrm{W}$, et al. Clinical and immunological features in a cohort of patients with partial DiGeorge syndrome followed at a single center. Blood. 2019;133:2586-96. https://doi.org/10.1182/ blood.2018885244 